\title{
Ménière's disease: the old and the new
}

Two articles in this issue of The Journal of Laryngology \& Otology address the dilemmas encountered in treating patients with Ménière's disease. The first of these is a comprehensive review of Ménière's disease from the Archives of the Journal. ${ }^{1}$ Flood and Kenyon trace the history of Ménière's disease from its original description to the present day, including a new magnetic resonance imaging scoring system for after intra-tympanic gadolinium injection. The article demonstrates beautifully the changing notions of aetiology for this condition and how these are reflected in the development of treatment modalities, most of which have fallen by the wayside. Another article reports the preliminary results of a cohort study of 26 patients with Ménière's disease unresponsive to standard first-line treatment, who were treated with oral Mycostatin. ${ }^{2}$ Although this study was uncontrolled, a number of patients reported improvement in various symptoms including vertigo, aural fullness, tinnitus and hearing loss. The authors concluded that treatment with Mycostatin showed some promise and that further controlled, prospective evaluation was needed.

Another two articles in this issue look at the problem of post-laryngectomy salivary fistula. Sousa and colleagues investigated the influence of early oral feeding on post-laryngectomy fistula in a randomised study of 89 patients. ${ }^{3}$ They found that although the incidence of salivary fistula was higher in the 'early feeding' group, this difference was not statistically significant. Invasive carcinoma at the resection margins was perhaps not surprisingly significantly associated with fistula formation. Powell and colleagues investigated the rate of post-laryngectomy fistula in patients undergoing salvage surgery following chemoradiation. ${ }^{4}$ Their recent practice has been to use tissue transfer in the neopharynx (pedicled or free flap), even in patients who have sufficient mucosa to allow primary closure. They found that patients who underwent this tissue transfer technique had a much lower rate of pharyngocutaneous fistula formation (in fact zero) than patients who underwent primary closure. The advantage of fistula formation reduction, in the authors' opinion, outweighed the additional operative time and potentially increased morbidity.

\section{ROBIN YOUNGS EDWARD FISHER Editors}

\section{References}

1 Flood LM, Kenyon G. Concepts of Ménière's disease in the Archives of The Journal of Laryngology and Otology. J Laryngol Otol 2014;128:308-17

2 Leong AC, Pothier DD, Rutka JA. Oral Mycostatin as a possible alternative treatment for intractable Ménière's disease: preliminary cohort study. J Laryngol Otol 2014;128:379-80

3 Sousa AA, Porcaro-Salles JM, Soares JMA, de Moraes GM, Silva GS, Sepulcri RA et al. Does early oral feeding increase the likelihood of salivary fistula after total laryngectomy? J Laryngol Otol 2014;128:372-8

4 Powell J, Ullal UR, Ahmed O, Ragbir M, Paleri V. Tissue transfer to post-chemoradiation salvage laryngectomy defects to prevent pharyngocutaneous fistula: single-centre experience. J Laryngol Otol 2014;128:365-7 